\title{
UNA REPRESENTACIÓN VISUAL DE LOS CHIRIGUANO EN LA EXPOSICIÓN MISIONAL DE TURÍN, 1898
}

\author{
POR \\ PILAR GARCÍA JORDÁN* \\ Universitat de Barcelona/TEIAA \\ pgarciajordan@ub.edu
}

\section{RESUMEN}

Las exposiciones misionales fueron escenario utilizado por la Iglesia católica para defender sus aportaciones al pensamiento, el arte, la cultura en general, y difundir la utilidad de la institución en la construcción de una sociedad civilizada y moderna. A partir de la colección, en particular de las fotografías relativas a las misiones entre los Chiriguano, enviada por Fr. Doroteo Giannecchini a la Esposizione d'Arte Sacra e delle Missioni e delle Opere Cattoliche (Turín, 1898), y del artículo dedicado a dicha colección por Amalia Capello en Arte Sacra (1898), se hará un estudio de la representación del grupo asentado en la actualidad en los departamentos de Chuquisaca, Tarija y Santa Cruz (Bolivia).

PALABRAS CLAVE: Guaraní; Chiriguano; representación visual; fotografías; exposiciones misionales; franciscanos.

\section{A VISUAL REPRESENTATION OF CHIRIGUANO IN TORINO MISSIONARY EXPOSITION, 1898}

\begin{abstract}
Catholic Church used missionary exhibitions in XIXth and Xxth centuries to promote its contributions to thought, art, culture and to spread the usefulness of the institution in building a modern and civilized society. This is a study of the representation of a native group settled in the present departments of Chuquisaca, Tarija and Santa Cruz (Bolivia), developped from the collection of photos on the missions among Chiriguano, sent by Fr. Doroteo Giannecchini to the Esposizione d'Arte Sacra e delle Missioni e delle Opere Cattoliche (Torino, 1898), and from the article dedicated to that collection by Amalia Capello in Arte Sacra (1898).
\end{abstract}

KEY WORDS: Guaraní; Chiriguano; visual representacion; photographies; missionary exposition; franciscans.

$\begin{array}{ll}\text { Recibido/Received } & 21-06-2013 \\ \text { Aceptado/Accepted } & 22-09-2014\end{array}$

"gente bárbara y salvaje, que primero debe hacérsela racional para que luego se convierta en cristianos, artesanos y ciudadanos". 1

* Este trabajo se inscribe en el proyecto de investigación I+D+i del MINECO (Ref. HAR2012-34095). El mundo latinoamericano como representación. La construcción de una representación política, social y cultural en América, 1880-1960 (Ref. HAR2012-34095), que se desarrolla en el seno del TEIAA (2014SGR532) grupo de investigación consolidado por el Comissionat per a Universitats i Recerca del DIUE de la Generalitat de Catalunya.

1 Afirmación de Giannecchini relativa al proceso reduccionista de los Chiriguano -gentilicio que utilizaré en el texto dado que era el nombre dado por entonces al grupo- en las misiones de Ivo y Cuevo. La secuencia discursiva relativa a los Chiriguano que de bárbaros y salvajes mutan en hombres racionales, cristianos, artesanos y ciudada-
Es bien sabido que la Iglesia católica de mitad del siglo XIX vio reducido sustancialmente su poder económico, su influencia social y política como consecuencia de la reducción temporal de los Estados Pontificios -derivada de la unificación italiana- $y$, sin duda más importante aún, de los procesos que dieron paso a las reformas liberales en Europa y en buena parte de los Estados latinoamericanos. Igualmente, hay acuerdo en señalar que tal situación obligó a la institución eclesial a realizar un aggiornamento, que se

nos, es aplicada reiteradamente por el autor en el relato que hace de la historia de la fundación de la mayoría de las misiones, trabajo inédito que fue editado por Calzavarini, Lorenzo, 1996. Historia natural, etnografía, geografía, lingüística del Chaco boliviano, 1898: 230.Tarija: Fondo de Inversión Social / Centro Eclesial de Documentación. 
produjo bajo el papado de León XIII, que pretendió, por un lado, sostener que la religión católica era compatible con el progreso científico; por otro lado, hacer de la iglesia católica una institución modernizadora y útil ya a los estados decimonónicos europeos en las tareas civilizatorias de las cuales éstos dijeron ser portadores en los diversos continentes en la etapa imperialista del último cuarto del siglo XIX, ya a los gobiernos latinoamericanos en las tareas igualmente civilizatorias involucrando a las poblaciones indígenas no sometidas hasta entonces ocupantes de la Amazonía, Chaco y Patagonia, entre otras. Y qué mejor lugar para demostrarlo que las exposiciones universales, internacionales y nacionales que se organizaron desde mediados del siglo XIX. ${ }^{2}$ Estas exposiciones, fueran cuales fuesen sus características, devinieron espacios de representación ${ }^{3}$ de las poblaciones indígenas para los misioneros que estaban desarrollando entre ellas sus estrategias civilizadoras a través de prácticas que utilizaron escritos -catecismos, gramáticas, diccionarios, etc.-, y cuyos resultados se mostraron en objetos de la cultura material, mapas, planos y fotografías. Prácticas entendidas aquí como formas de hacer en que se desarrolla un determinado universo simbólico que, en el caso que nos ocupa en este texto, afecta a las acciones realizadas por los misioneros franciscanos entre los Chiriguano. Acciones que, como señala Dube, a partir de las reflexiones sobre lo cotidiano realizadas por de Certeau, conforman "escenarios de producción, negociación, transacción y contestación de significados dentro de redes y relaciones de poder mayores". ${ }^{4}$

A partir del análisis de caso ofrecido por la Esposizione d'Arte Sacra e delle Missioni ed delle Opere Cattoliche celebrada en Turín en 1898, el objetivo de este artículo es analizar la representación de los entonces denominados Chiriguano -y que hoy conocemos como Ava-Guaraní-, ubicados en los departamentos de Chuquisaca, Tarija y Santa Cruz, en Bolivia, a través de la colección enviada al certamen por el prefecto misionero, Fr. Doroteo Giannecchini, otrora superior de las misiones entre aquéllos. ${ }^{5}$ Centraré mi análisis en una serie

2 Véase Findling, John E. y Pelle, Kimberly D. (eds.) 2008. Encyclopedia of World's Fairs and Expositions. Jefferson /Londres, Mc Farland \& Company: Inc. Publishers; Greenhalgh H, Paul, 1988. Ephemeral vistes. The expositions universelles, great exhibitions and world's fairs, 1851-1939. Manchester: Manchester University Press.

3 En la representación se encuentra una doble operación, transitiva y reflexiva; mientras la primera nos presenta los objetos ausentes a través de imágenes, gestos, palabras, la segunda concierne al acto de exhibir la propia presencia, de autorepresentarse. Véase Marin, Louis, 1981. Le Portrait du Roi. París: Editions de Minuit; Chartier, Roger, 1992. Historia Cultural: entre práctica y representación. Barcelona: Editorial Gedisa.

Dube, Saurabh, 2001. Sujetos subalternos: Capítulos de una historia Antropológica: 26. México: El Colegio de México. Algunos de los estudios útiles para el abordaje teórico de las prácticas son, entre otros, Marin, Louis, 1994. De la représentation: 23-45. París: Gallimard/Le Seuil; De Certau, Michel, 2000. "Teorías del arte de hacer" en M. de Certau, 2000. La invención de lo cotidiano. México, Universidad Iberoamericana/Instituto Tecnológico y de Estudios Superiores de Occidente. Vol. 1, y también la lectura que de éstos hace Chartier, Roger, 1996. Escribir las prácticas. Foucault, de Certeau, Marin. Buenos Aires: Manantial.

5 Relación de los 500 objetos, las fichas explicativas correspondientes y las fotografías en Calzavarini, 1996: 57. Giannecchini, nacido en un pueblecito de Lucca en 1837, llegó a Bolivia en 1860 como misionero franciscano, fue ordenado sacerdote y tras aprender el idioma chiriguano, fue destinado (1862) a Tarairí, más tarde a Caiza y San Francisco Solano, todas ellas misiones en el Chaco. Tras ser nombrado co- de fotografías, con sus correspondientes leyendas, con una doble lectura; por un lado, la realizada por el religioso sobre una población entre la que había desarrollado actividades misioneras a lo largo de 36 años y que debía ser mostrada a la heterogénea población que visitara la exposición turinesa a la que se enviaron un total de 115 fotografías; por otro lado, la desarrollada por Amalia Capello, autora del artículo dedicado a las misiones entre los Chiriguano en dicho certamen y en el que se incluyeron 7 de dichas fotografías. ${ }^{6}$ De ahí que el análisis comparativo exige centrarse exclusivamente en las imágenes recogidas en el texto de Capello y considerar, además, que la elección de fotografías, mejor de un conjunto de ellas -en este caso la realizada por la autora italiana a partir del conjunto de imágenes enviadas por Giannecchini y reproducidas en Turín- obedece al interés por transmitir un determinado mensaje en el que texto y fotografía se articulan en un relato discursivo.

Las hipótesis aquí planteadas son que el relato etnológico construido por Giannecchini y del que participa Capello es el positivista, dominante en el pensamiento europeo finisecular, en el que las tesis evolucionistas aplicadas a la sociedad permiten plantear el paso de la barbarie a la civilización, del bárbaro y salvaje al de cristiano y ciudadano, y las categorías utilizadas por ambos autores tienen que leerse en esa clave ideológica. En el caso concreto de las fotografías, éstas fueron utilizadas como evidencia visual del proceso civilizatorio narrado en los textos al mismo tiempo que instrumento para otorgar objetividad al relato en línea con lo que estaban haciendo antropólogos, geógrafos, médicos, etc. en la Europa finisecular. Con todo, hay diferencias significativas, la fundamental es que el relato -texto y fotografías- de Giannecchini es concreto y específico referido al proceso civilizatorio implementado por los franciscanos entre los Chiriguano; por el contrario, Capello realiza una generalización, una abstracción que afecta a todos los misioneros que desarrollan sus actividades entre las poblaciones salvajes.

Nos será particularmente útil aquí la propuesta teórica de Poole relativa a la por ella denominada economía visual que involucra tres niveles de organización, la organización de la producción que implica a individuos y tecnologías que producen imágenes; la circulación de imágenes

lector para la exposición (1896), viajó a Turín (1897-1898) y, al regreso, permaneció en el convento de Tarija hasta 1900, cuando murió. Véase Calzavarini, Lorenzo, 1995. "Introducción”, en Álbum fotográfico de las misiones franciscanas en la República de Bolivia, a cargo de los Colegios Apostólicos de Tarija y Potosí, 1898, dedicado a Luis Paz. 1995: 5. La Paz: Ed. Banco Central; Calzavarini, Lorenzo. 1996: 41 pássim.

6 Capello, Amalia, 1898. "Le Missioni Francescane nell'America del Sud. Bolivia e chireguanos", en Arte Sacra: 146-150. Torino: Roux Frassati e Co. Capello es autora de numerosos opúsculos sobre la actividad de los misioneros italianos en América del Norte y del Sur, África y Asia, algunas historias locales turinesas e incluso cuentos, publicaciones hechas entre 1896 y 1939. Carezco de más datos sobre la autora, aunque una Amalia Capello, turinesa, condesa casada con un diplomático nicaragüense, es mencionada en un relato referido a la elevación de Don Bosco por la iglesia católica como Beato (2 de junio de 1929). En este acto, Capello pronunció un discurso en la fiesta organizada por los Josefinos, con asistencia de diversos representantes diplomáticos y autoridades romanas, en el que "La oradora, señora de fina cultura y muy conocida en los ambientes romanos, correspondió felizmente al encargo que se le había confiado" en Memorias biográficas de Don Bosco, [versión en español] Vol. 19, p. 119, en http://www. dbosco.net/mb/mbvol19/mbdb_vol19_119.html. Consultado 14 de mayo de 2013) 
cual mercaderías; y los sistemas culturales y discursivos mediante los que las imágenes son estudiadas, interpretadas y a las que se asigna un valor histórico, científico y estético. ${ }^{7}$ Coincido con Poole cuando señala que el ver y el representar son actos materiales, en tanto medios de intervención en el mundo, y "the specific ways in which were (and represent) the world determine how we act upon that world and, in so doing, create what that world is. It is here, as well, that the social nature of vision comes into play, since both the seemingly individual act of seeing and the more obviously social act of representing occur in historically specific networks of social relations". ${ }^{8}$ En igual medida conviene tener presente los estudios recientes acerca del uso que diversas disciplinas hicieron de las fotografías como método de observación, clasificación y "como un medio para fabricar la objetividad científica en sí misma", interés que, como veremos, también estuvo presente en la muestra turinesa.

En consecuencia, tras unas muy breves consideraciones sobre la Esposizione Generale e dell'Arte Sacra, delle Missioni e delle Opere Cattoliche, abordaré la representación de los Chiriguano en las fotografías hechas expresamente para ser expuestas en el certamen turinés, deteniéndome en particular en las siete imágenes recogidas en el artículo de Capello. Ello exigirá una reflexión sobre las características de los textos en los que se incluyeron aquellas fotografías -el manuscrito enviado por Giannecchini a la Exposición misional, y el escrito redactado por Capello sobre la presencia chiriguana en el certamen- y el contexto histórico en el que las imágenes fueron realizadas y expuestas.

Poole, Deborah. 1997. Visions, race, and modernity: a visual economy of the Andean image world. Princeton: Princeton University Press. Referencias ineludibles sobre la fotografía y su utilización como documento histórico son los estudios de Barthes, Roland. 1989. La cámara lúcida. Nota sobre la fotografía. Barcelona: Paidos; Burke, Peter. 2001. Visto y no visto. El uso de la imagen como documento histórico. Barcelona: Crítica y Sontag, Susan.1996. Sobre la fotografía. Barcelona: Edhasa.

8 lbídem: 7. Consideramos, además, que las fotografías, en tanto imágenes, se construyen a partir de una política de la representación que se desarrolla en un contexto de relaciones de poder determinado y en la que la representación es una forma de producción y reproducción del poder y, al mismo tiempo, expresión de un ordenamiento específico. Sin embargo, me distancio de aquellos análisis en los cuales la mirada es vista, exclusivamente, como instrumento unilateral de dominación y control pues, como también señala Poole, el uso político de las imágenes exige comprender las, frecuentemente, contradictorias relaciones, sentimientos, actitudes, etc., con que los pueblos confieren a las imágenes, específicos significados y valores.

Zamorano Villarreal, Gabriela. 2011. "Fisonomía de traidor: Fotografía y la racialización de los indígenas bolivianos por la expedición Créqui-Montfort (1903)". Anuario de estudios bolivianos, archivísticos y bibliográficos, 17: 638. Útiles estudios sobre el uso de la fotografía como medio para consolidar la idea de raza al tiempo que para validar aquélla como herramienta científica son, entre otros, Brau, Marta. 2007. "La photographie et les sciences de l'observation (1845-1900)", en André Gunthert and Michel Poivert (eds.). L'art de la photographie des origines à nos jours: 140-177. París: Citadelles \& Mazenod; Edwards, Elizabeth (ed.) 1992. Anthropology \& Photography, 1860-1920. New Haven: Yale University Press; Edwards, Jeanette; Harvey, Penny; Wad, Peter (eds.). 2010. Technologized Images. Technologized Bodies. Oxford: Berghahn Books; Pauwels, Luc (ed.). 2006. Visual Cultures of Science: rethinking representational practices in knowledge building and sciences communication. Hanover: University Press of New England.

\section{LA ESPOSIZIONE GeNERALE E DELL'ARTE SACRA, DELLE MISSIONI E} DELLE OPERE CATTOLICHE DE TURÍN, 1898

Es sabido que tras la exposición en el Crystal Palace londinense (1851) de las más importantes novedades industriales, avances tecnológicos, etc. por los países que participaron en la Gran Exhibición, las sucesivas exposiciones, congresos y ferias internacionales sirvieron para dirimir la supremacía económica, política y cultural entre los países implicados en la carrera del progreso que, ya en el último cuarto, devino en diversos proyectos neocoloniales en Asia, África y, en menor medida, América Latina. ${ }^{10}$ Posteriormente, fueron muchas las exposiciones de carácter internacional, nacional y regional que se organizaron en los países europeos y los Estados Unidos de Norteamérica, algunas de ellas con proyección colonial, de ahí la denominación de exposiciones coloniales.

Inicialmente no hubo participación de las iglesias cristianas, y en particular la católica, ${ }^{11}$ en estos certámenes, tanto por la resistencia de aquéllas a participar en eventos rendidos al progreso material como por las reticencias de éstos hacia el mundo religioso. La situación cambió en la década de 1890 y en un contexto en que, generalmente, aparecieron como instrumentos de la expansión colonial. ${ }^{12}$ Sin entrar por el momento en esta cuestión, sabemos que la Iglesia católica y las instituciones protestantes aprovecharon también esos espacios ya para defender las aportaciones realizadas por ellas en el campo del pensamiento, el arte, etc., ya para difundir la utilidad de aquéllas en la construcción de una sociedad civilizada y moderna a través de las misiones. En el caso del certamen turinés, en tanto exposición general tuvo un carácter nacional y estuvo destinada a fortalecer el espíritu que permitió la unificación y el surgimiento del Estado italiano promovido desde el Piamonte; y, en cuanto promovido por la Iglesia y los sectores católicos turineses, pretendió mostrar la contribución de la religión y de la institución eclesial al arte, al pensamiento y a la cultura italiana y a la civilización de los pueblos infieles y salvajes a través de la actuación de los misioneros italianos en el mundo.

No me detendré aquí sobre los aspectos significativos del origen, los objetivos y las características físicas de la Esposizione que he tratado con mayor detenimiento en otro trabajo. ${ }^{13}$ Sí me interesa señalar que los datos más relevantes sobre la muestra figuraron en la guía redactada en 1898 por A. Gulinelli y en los 40 números del Giornale publicados

10 Rydell, Robert W. 1984. All the World's a Fair. Visions of Empire as American International Exposition, 1876-1916. Chicago: The University of Chicago Press.

11 Para el caso de las iglesias protestantes véase Burris, John P. 2001. Exhibiting Religion: Colonialism and Spectacle at International Expositions 1851-1893. Charlotesville/Londres: University Press of Virginia; para la católica, Yengoyan, Aram. 1994. "Culture, Ideology and World's Fairs: Colonizer and Colonized in Comparative Perspectives", en R. W. Rydell y N. Gwinn (eds.). 1994. Fair Representations: World's Fairs and the Modern World: 62-83. Amsterdam: VU University Press.

12 Sánchez Gómez, L. A. 2011. “Imperialismo, fe y espectáculo: la participación de las iglesias cristianas en las exposiciones coloniales y universales del siglo XIX". Hispania, LXXI, 237: 153-180.

13 García Jordán, Pilar. 2012. "La representación de los Guarayos en la Esposizione d'Arte Sacra e delle Missioni ed Opere Cattoliche' (Turín, 1898)". Boletín Americanista, LXII.2, 65: 107-129. 
después en forma facsimilar. ${ }^{14}$ El certamen incluyó, por un lado, la llamada Exposición General, reuniendo más de 10.000 expositores sobre las actividades productivas -agrícolas, industriales, comerciales- de la península italiana, en particular de la región del Piamonte; el asociacionismo relativo a la previsión y asistencia social e higiene, como no podía ser menos en una región pionera en la industrialización del país; y la emigración italiana. Por otro lado, la Exposición de Arte Sagrada, de las Misiones y de las Obras Católicas, reuniendo una muestra del arte sagrado antiguo y moderno; de las misiones desarrolladas por los italianos en el mundo; y de las obras implementadas en el ámbito católico relativas a la protección y ayuda a los sectores sociales más desfavorecidos.

El certamen turinés requirió la construcción de diversos edificios que se ubicaron junto al Po en el llamado Parco Valentino. La Exposición de Arte Sacro, de las Misiones y de las Obras Católicas exigió la erección de diversos edificios en los que se mostraron los objetos y utensilios traídos de América, Tierra Santa, Imperio Otomano y África, además de estatuas y grupos escultóricos, ${ }^{15}$ y de la presencia de un total de 120 indígenas, 8 de los cuales procedentes de las misiones americanas -3 del Mato Grosso brasileño y 5 del Chaco boliviano- ${ }^{16}$ sobre los que volveré más adelante. Todo ello permite hablar de la muestra turinesa como ejemplo de exposición viva ${ }^{17}$ Finalmente, si como he dicho líneas

14 Gulinelli, A. 1898. Guida dell' Esposizione Generale dell'Arte Sacra in Torino con Pianta della Città e delle Esposizioni, compilata dal Cav. Avv. -, Sotto Segretario della Camera di Commercio di Torino già Direttore degli Uffici sull'Esposizione 1884. Torino/Roma/Milano/ Firenze/Napoli: Ditta G. B. Paravia e Comp y Arte Sacra. 1898. Declaración de intenciones acerca del objetivo, contenido, calidad de las contribuciones, etc. del Giornale en Arte Sacra, 1898: 2. La obra final incluyó 220 entradas -breves artículos-, redactadas por 50 autores, y un total de 243 ilustraciones (fotografías, mapas, planos, sellos conmemorativos).

15 Según se dijo en el Giornale "la maggior parte del pubblico si ferma attonito innanzi alle statue in grandezza naturale, rappresentanti i tipi indigeni delle diverse razze, evangelizzate dai Missionari" en Arte Sacra. 1898: 305. Torino: Roux Frassati e Co. Estudio de estos grupos escultóricos, en particular las habitaciones etnográficas, en Stoklund, Bjarne. 1994. "The role of the International Exhibitions in the construction of national cultures in the 19th. Century". Ethnologica Europaea, Upsala, 24(1): 35-44.

16 Gulinelli, A. 1898. Guida dell' Esposizione Generale dell'Arte Sacra in Torino con Pianta della Città e delle Esposizioni, compilata dal Cav. Avv. -, Sotto Segretario della Camera di Commercio di Torino già Direttore degli Uffici sull'Esposizione 1884: 34. Torino/Roma/Milano/ Firenze/Napoli: Ditta G. B. Paravia e Comp.; Calzavarini, Lorenzo. 1996. Historia natural, etnografía, geografía, lingüística del Chaco boliviano, 1898: 57. Tarija: Fondo de Inversión Social/Centro Eclesial de Documentación.

17 Luis Ángel Sánchez Gómez señala como tales aquéllas en "las que se presentan seres humanos como parte intrínseca del evento", véase su artículo "Martirologio, etnología y espectáculo: la Exposición Misional Española de Barcelona (1929-1930)". Revista de Dialectología y Tradiciones Populares, LXI, 1: 65. Hoy sabemos que las exposiciones vivas se produjeron en el ámbito protestante (Coombes, Annie E. 1994. Reinventing Africa: Museums, Material Culture and Popular Imagination in Late Victorian and Edwardian England. New Haven/Londres: Yale University Press; Erlmann, Veit. 1999. "«Spectatiruak Kyst»: The African Choir in England, 1891-1893", en Lindfords Bernth (ed.). African on Stage: Studies in Ethnological Show: 107-134. Business. Bloomington: Indiana University Press). Y también en el ámbito católico, en Génova y Turín (Bottaro, Mario. 1984. Genova 1892 e le celebrazione colombiane. Génova: Francesco Pirella Ed.; Zaccone, Gian Maria. 1996. arriba, el objetivo de la exposición misional turinesa fue la propaganda de la actividad desarrollada por los misioneros italianos allá donde hubiera poblaciones infieles, algunas de ellas salvajes, sólo queda hacer unas consideraciones sobre el contenido de la muestra y el relato etnológico desarrollado en la misma. Por cuanto se refiere al primero, se expusieron "ricche collezioni di libri, e di manoscritt, coi quali dimostrano il metodo tenuto per istruire ed educare i selvaggi"18 que mostraban las prácticas desarrolladas por los misioneros de las órdenes religiosas presentes-capuchinos, franciscanos y salesianos-. Por lo que respecta al segundo, el ordenamiento de las colecciones en el certamen construía un relato articulado por imágenes de inferioridad y primitivismo que, dicho sea de paso, estaban entonces presentes tanto en la etnología religiosa como en la etnología laica que participaban del pensamiento evolucionista dominante. ${ }^{19}$ En éste, uno de los ingredientes fundamentales era la noción de raza que se basaba en tipos físicos y se asociaba a cuestiones culturales y ambientales, asumiendo en general que las sociedades primitivas podían devenir sociedades civilizadas a partir del correspondiente proceso civilizatorio, lo que venía a justificar la expansión colonialista por entonces en acción.

En suma, en el certamen se mostraron, por un lado, los aspectos más significativos de las poblaciones salvajes -descripciones etnográficas de los mismos, objetos de la vida material- y de los territorios en que se encontraban -mapas-; por otro lado, los medios utilizados para la implementación del plan misional, a través de prácticas en que se desarrollaba el universo simbólico del que eran portadores los religiosos -gramáticas y diccionarios de las lenguas indígenas, catecismos, planos de las misiones que mostraran la apropiación simbólica del espacio indígena realizado por la misión (templo, escuelas, talleres, casas)-; finalmente, los resultados del proyecto, fuera con objetos de la vida material y fotografías e, incluso, con la presencia física de algunos individuos como muestra evidente de haber dejado atrás su salvajismo y entrado en la civilización.

La convocatoria de la comisión organizadora de la Exposición de Arte Sacra fue muy bien recibida por las diversas órdenes religiosas que desarrollaban actividades misioneras en Asia, África y América, a quienes se solicitó recabaran de los prefectos misioneros la recolección de personas y objetos materiales - prueba fehaciente de la actuación misional- que permitieran a los visitantes del evento hacerse una idea del territorio, la geografía y la etnografía de las poblaciones indígenas con particular referencia a la lengua, la cosmovisión y las actividades económicas. Giannecchini, nombrado, en 1897, Colector para la

\footnotetext{
"L'Esposizione d'arte sacra del 1898 a Torino tra religione e politica". Studi Piamontesi, XXV-1: 71-102). Ver también la obra resultado de la exposición celebrada en el museo de Quai Branly sobre la presencia de seres humanos procedentes de diversos continentes en exhibiciones circenses, cabarets, etc, Blanchard, Pascal; Boëtsch, Gilles; Snoep, Nanette J. (eds.). 2011. Exhibitions. L'invention du sauvage. París: Actes Sud/Musée du Quai Branly.

18 A.C. 1898 . "Gli oggetti esposti nella Mostra delle Missioni", en Arte Sacra: 305. Torino: Roux Frassati e Co.

19 Véase Sánchez Gómez, Luis Ángel. 2007. “Por la Etnología hacia Dios: la Exposición Misional Vaticana de 1925". Revista de Dialectología y Tradiciones Populares, LXII, 2: 104.
} 
exposición turinesa por sus superiores, ${ }^{20}$ redactó, a partir de las notas por él tomadas en el pasado y completadas en el transcurso de los meses sucesivos, un manuscrito -escrito en italiano y que firmó como "misionero colector exposicionario"- que mandó a Turín, junto con las fotografías solicitadas por la comisión organizadora del evento, antes del viaje que realizó el mismo a la ciudad piamontesa en compañía de cinco jóvenes chiriguanos/as, cuya presencia había sido requerida por los superiores franciscanos. ${ }^{21}$

\section{LA REPRESENTACIÓN DE LOS CHIRIguANO EN TURÍN, 1898}

Como señalé al inicio, antes de analizar las fotografías conviene hacer algunas consideraciones sobre los dos textos en los que aquéllas estaban insertas para, a continuación, abordar brevemente el contexto histórico en que unos y otras fueron realizados.

\section{Los textos}

"La etnografía que presentamos a continuación se refiere únicamente a la nación chiriguana salvaje, que tienen a su cargo los Colegios de Propaganda Fide de Nuestra Señora de los Ángeles de Tarija y de San Antonio de Potosí. // [...] Las últimas reliquias o avances de esta nación, otrora tan numerosa, nosotros [misioneros de Tarija] y nuestros hermanos de Potosí, las hemos reducido a Misión. Las demás aldeas de los mismos fueron vencidas y sometidas por las armas bolivianas de tal manera que, hablando con propiedad, la Nación Chiriguana ahora ya no existe en su más puro y neto salvajismo". ${ }^{22}$

La frase corresponde al primero de los textos objeto de este trabajo, el manuscrito, preparado por Giannecchini en italiano y por él titulado, Collezione Sanfrancescanna di storia naturale, etnografía, geografía, lingüística dei Collegi di Propaganda Fide di Santa Maria degli Angeli di Tarija e di San Antonio di Padova di Potosí (Bolivia) America Meridionale, que es una relación de 12 fichas explicativas enviadas al comité organizador del certamen misional turinés. ${ }^{23}$ En ellas el religioso respondía a los requerimientos de la comisión organizadora de la exposición misional, en

20 La Curia Generalicia se sirvió del Acta Ordinis y de circulares enviadas a los comisarios generales de la orden en todos los países donde los franciscanos ejercían sus actividades. En el caso boliviano fue P. Sebastián Pifferi, comisario general de los Colegios de Propaganda Fide en Bolivia, quien encargó al P. Doroteo Giannecchini la recolección de todo el material relativo a las misiones dependientes del colegio misionero de Tarija y de Potosí. Véase Calzavarini, Lorenzo. 1996: 51.

21 Aspectos relativos a la redacción de las notas, el manuscrito final y los avatares del mismo en Turín en Calzavarini, Lorenzo. 1996: 54 pássim.

22 Giannecchini en Calzavarini, Lorenzo. 1996: 293-294.

23 La Colección de Historia Natural (Fichas I a IV sobre fósiles, minerales, vegetales, animales); las Colecciones etnográficas, históricas y geográficas (Fichas V a VIII sobre tejidos, textos relativos a los Colegios de Potosí y Tarija, historia de las misiones de ambos colegios), y notas relativas a la Geografía, Etnografía, Religión y Lenguas de los Chiriguano (Fichas IX a XII). Según anota Calzavarini, las fichas VI, VII y VIII no han sido precisadas como tales en el manuscrito original. La publicación del manuscrito, en 1996, fue posible gracias al esfuerzo de Lorenzo Calzavarini, 1996. forma de cuestionario, sobre el territorio, la geografía y el hábitat, la cultura material, la etnografía, el sistema político, la religión y la lengua de los Chiriguano. ${ }^{24}$ Se valió para ello de su experiencia y de los trabajos sobre estos temas publicados por científicos, exploradores, intelectuales varios y misioneros. ${ }^{25}$

No es el momento de analizar, con detenimiento, el relato etnológico positivista construido por el religioso, en el que se utilizan categorías con significados bien precisos en ese contexto aplicadas a las entonces llamadas sociedades primitivas, tales como bárbaro y salvaje. Según Calzavarini, en una lectura interesada del texto de Giannecchini, tales conceptos "más que definiciones de una situación socio-cultural chiriguana, son condiciones para aquellos que llamándose 'civilizados' rompen toda norma der buena vecindad con los mismos [los Chiriguano]". ${ }^{26}$ No comparto la primera parte de la afirmación de Calzavarini, ${ }^{27}$ aunque sí la segunda por cuanto Giannecchini, como otros religiosos que desempeñaron sus actividades misionales en territorios donde se enfrentaron lo que se dio en llamar la civilización y la barbarie -fuera en contextos imperialistas o en la implementación del estado-nación-, constatando que los objetivos misioneros entraban en contradicción con los perseguidos por los grupos dirigentes -domesticación de la mano de obra indígena prioritariamente-, criticó reiteradamente la posición de los colonos barbarizados. Sin embargo, me parecen claros los significados de las categorías utilizadas reiteradamente por el autor de la Colección San Franciscana en el relato de la por él llamada generalmente conquista y reducción de los Chiriguano; significados y categorías que eran compartidas por buena parte de la antropología y de las ciencias sociales en general, de fines de siglo XIX. Para Giannecchini, los Chiriguano eran "gente feroz y salvaje", 28 "bárbaros", "hombres de la selva", que salen "de sus matorrales", 29 "hordas salvajes" 30 a quienes el misionero -"verdadero civilizador de los pueblos", como señala en otro momento de la narración- ${ }^{31}$ debía convertir en "hombres

24 Giannecchini incluyó también en el manuscrito, como apéndice, una Etnografía Noctena.

25 Al parecer, Giannecchini sólo realizó un borrador del manuscrito que se conserva en el Archivo franciscano de Tarija en Calzavarini, Lorenzo. 1996: 54.

26 Calzavarini en Álbum. 1995: 14; afirmación repetida en Calzavarini, Lorenzo. 1996: 59-60. Un párrafo que resume bien la posición de Giannecchini al respecto de los que denomina, frecuentemente, como "mestizos barbarizados" en Ibídem: 228, 249, escrita a propósito de la fundación de Chimeo que generaliza para el resto: "Para no tener que repetir siempre lo mismo para cada misión, hagamos notar de una vez por todas, que los misioneros de América en general y los de Tarija en particular, han tenido que soportar odios, persecuciones, expoliaciones y toda suerte de villanías por parte de los mestizos [colonos] y de los mismos bárbaros e indios salvajes; [...] los católicos mestizos, que pretendían propagar su Fe contra los bárbaros, los mestizos de toda condición de los alrededores de las antiguas y nuevas fundaciones de las misiones de infieles, fueron siempre ministros de Satanás, dispuestos a destruir, con sus palabras y con sus actos lo que los ministros de Dios y de la Iglesia habían edificado [...]" (Ibídem: 162).

27 La lectura de Calzavarini atiende más al carácter "pastoral" de la actividad misionera de Giannecchini que al pensamiento "antropológico" del mismo.

28 Doroteo Giannecchini en Calzavarini, Lorenzo. 1996: 162.

29 Ibídem: 210.

30 Ibídem: 224

31 Ibídem: 177. 
útiles a sí mismos, a la religión y a la patria". ${ }^{32}$ Los conceptos y el relato del que estos forman parte se repiten a lo largo de la historia en que Giannecchini narra los hechos que llevan a la fundación de todas las misiones entre los Chiriguano. ${ }^{33}$

El segundo texto es el artículo de Amalia Capello, "Le missioni francescane nell'America del Sud. Bolivia e Chiriguanos", incluido en la publicación derivada del certamen. ${ }^{34}$ Según Calzavarini, el escrito fue redactado "basándose en las fotografías" ${ }^{\prime 35} \mathrm{y}$, probablemente, haya algo de cierto en ello aunque de la lectura se desprende que la autora consultó el material enviado por Giannecchini a Turín. En todo caso, el artículo incluye un total de 7 fotografías de las cuales 6 corresponden a la colección enviada por aquél. ${ }^{36}$

Por cuanto se refiere al relato, la narración de Capello, tras unas consideraciones generales sobre las actividades misionales de la orden franciscana en general, y en América del Sur en particular, describe algunos aspectos del plan desarrollado por los religiosos entre las "tribus" que se encuentran "al ultimo grado di barbarie" en "tante foreste quasi inesplorate"; es en ellas, agrega Capello, donde han buscado refugio los indígenas ante el avance de los conquistadores y poblaciones blancas y mestizas, interesados por el territorio pero no por "I'anima immortale". ${ }^{37} \mathrm{Y}$, a propósito de los Chiriguano, cuestión que a nosotros aquí interesa, refiere la presencia en la exposición de una "familia de 5 Chireguanos [sic] (Bolivia), che puo dare un'idea dell'opera constante dei Missionari" ${ }^{38}$ y enumera algunos de los aspectos del grupo tales como su procedencia del Paraguay, uso de la lengua guaraní, elementos de su cosmovisión, deteniéndose en algunos detalles etnográficos que, dice, son "ilustrados" en las imágenes (bailes en torno a vasijas con chicha, vestidos utilizados, etc.). Las categorías utilizadas por la autora son las propias del discurso positivista y del relato etnológico evolucionista, de civilización frente a barbarie. Buen ejemplo de ello nos ofrece el pasaje relativo a la presencia viva de una familia de chiriguanos ${ }^{39}$ que, en palabras de Capello:

\section{Ibídem: 166.}

33 Con todo, tal afirmación no me impide coincidir con lo señalado por uno de los evaluadores de este artículo quien considera a Giannecchini como un "proto-etnógrafo" que en sus obras manifestó una percepción etnográfica y lingüística inusual en su época, avanzada de la realidad multicultural que se desarrollaría muchas décadas después.

34 Capello, Amalia. 1898: 146-150.

35 Calzavarini, Lorenzo. 1996: 63.

36 Asumo, como he señalado al inicio, que las fotografías incluidas fueron seleccionadas por Capello, a quien atribuyo también los correspondientes pies de foto. Estas dos cuestiones podrían no ser ciertas, lo que no invalidaría nuestra tesis dada la coherencia entre el discurso escrito, la representación visual y el pie de la fotografía.

37 Capello, Amalia. 1898: 147.

38 Ibídem: 146.

39 El comité organizador de la exposición misional turinesa había demandado de las órdenes religiosas que enviaran al certamen representantes de las poblaciones destinatarias del proyecto evangelizador y civilizador, ejemplo del éxito de los proyectos misionales. Véase sobre las llamadas exposiciones vivas la nota 18. Respecto la presencia de indígenas en las exposiciones misionales (Génova en 1892 y Turín en 1898), Sánchez Gómez, Luis Ángel. 2011: 169 y 171, sostiene que tal presencia tenía un carácter "animalizador" aunque, a diferencia del espectáculo montado en la muestra genovesa, dicha presencia obedeció a un interés informativo y ejemplarizante. Compartiendo la idea que la exhibición presentaba algunos elementos similares a aquellos
"E composta di due giovani sposi e di alcuni loro parenti. Il marito, dal viso ingenuo, senz'ombra di barba pare un fanciullo. La moglie ha lunghi Capelli, una fisonomía simpatica, ma un po'sofferente. É avvolta, come pure le cugine che l'hanno accompagnata, in un lungo zendado a fiorami, il quale scende dalla testa ai piedi, e cosi acconciate rassomigliano a donne orientali. // Lo sposo, Antonino, e Fortunato, il parente che venne seco, sono invece vestiti all'europea, e solo si distinguino per uno scialle che a guisa di poncho, si gettano sulle spalle. // II loro tipo é l'indiano assai pronunciato. Sono cortesi coi visitatori, e sebbene nei loro occhi si legga un intenso desiderio delle tropicali foreste, pure si arrendono docili e mansueti alla voce del Padre, il quale li persuade che debbono fermarsi fino al termine dell'Esposizione. Ed essi si fermano, lieti quando assistono a solenni funzioni religiose, che parlano potentemente al loro cuore pieno di fede. É la grazia, é la fatica continua del Padre Missionario, che hanno cambiato questi selvaggi feroci in ottimi cristiani, ma per bene intendere la loro trasformazione, bisogna parlare col Padre Doroteo Giannecchini". ${ }^{40}$

Me interesa notar en este párrafo, por un lado, la tesis relativa a la transformación de los bárbaros habitantes de los bosques en civilizados. Efectivamente, aquellos "tipos indios" -vestidos con túnicas ellas y a la europea ellos- se muestran "corteses", "dóciles" y "sumisos", no rebeldes, y buenos cristianos - "felices" y con el "corazón lleno de fe" en las ceremonias religiosas. Esa mutación de bárbaro a civilizado ha sido realizada por los misioneros franciscanos- la referencia concreta a Giannecchini deviene, en el texto de Capello, general para todos los misioneros, tratando así de conseguir un efecto de objetividad, con la utilización de las categorías a las que antes me refería. Por otro lado, la invención que hace Capello al informar de la existencia de relaciones familiares entre los Chiriguano - una pareja de esposos, acompañados por dos primas de la mujer y un varón cuyo parentesco no se señala-. Sabemos, por la narración de Giannecchini, que el grupo no era una "familia" y, en realidad, estaba conformado por 3 jóvenes mujeres (residentes en las misiones de Aguairenda, San Francisco Solano y Tacuarí) y 2 varones jóvenes (residentes en Aguairenda). ${ }^{41}$ Desconocemos las razones de la invención aunque una hipótesis plausible es aquélla que propone a los "jóvenes esposos", por ende la familia cristiana, como la culminación de este proceso transformador de "feroces salvajes" en "óptimos cristianos" llevada a cabo por los misioneros. Por el contrario, la inexistencia de lazos familiares entre cinco jóvenes de ambos sexos podría dar lugar a interpretaciones distorsionadas por un público lector, católico, que compartía un imaginario en el que la secuencia salvaje-desnudez-sexualidad adquiría sentido. ${ }^{42}$

espectáculos en que se contaba con la presencia de individuos exóticos $y$, en el peor de los casos, con atributos físicos fuera de la norma en circos y otros espacios, discrepo acerca del carácter "animalizante" de la muestra turinesa.

40 Capello, Amalia. 1898: 147.

41 Existe una fotografía de la supuesta familia, realizada en Turín, en la que, en torno a un banco en el que está sentado Fr. D. Giannecchini aparecen, tras una pequeña empalizada sobre la que se apoyan, las jóvenes chiriguanas Petronila Tayo, Prudenciana Mbaisseiru, María Capairu, y los varones Teófilo Yambire y Fortunato Cuarassimimmi, quien aparenta sonar una flauta (Calzavarini, Lorenzo. 1996: 52).

42 Uno de los evaluadores señala que la información disponible nos impide saber realmente si esos cinco indígenas eran o no familia -en el significado que en la cultura occidental le damos al vocablo- 
En suma, en línea con el pensamiento positivista, Capello asumía que sociedades primitivas y salvajes, como la chiriguana podían devenir sociedades civilizadas. De ahí que yo sostenga que el discurso elaborado por la autora italiana, en sintonía con los objetivos perseguidos por los organizadores de la Exposición misional, publicitaba la acción misionera de los franciscanos -mediadores culturales- para la transformación de los salvajes chiriguanos en individuos civilizados. Para ello Capello hacía, de un caso concreto, una generalización, una abstracción que afectaba a todas las misiones católicas, como constataremos también en las fotografías. Hechas las consideraciones sobre el texto, pasemos a reflexionar sobre el contexto.

\section{Los contextos}

"He aquí cómo estas manos muertas, [los misioneros] de estos montes hacen jardines, de rudos y bárbaros salvajes que hacían y hacen temblar y desfallecer de miedo a los vecinos mestizos, pueden transformar en hombres racionales, artesanos, útiles a la Iglesia y al Estado". ${ }^{43}$

Las palabras de Giannecchini nos llaman la atención sobre la importancia de la actividad misional en la Bolivia finisecular en la que todavía resonaban los ecos de los sucesos de Kuruyuki de 1892, episodio que vio el feroz enfrentamiento entre las fuerzas del prefecto Ramón González y del subprefecto de Azero, Tomás Frías y los Chiriguano concentrados en Kuruyuki, cerca de Ivo. ${ }^{44} \mathrm{El}$ "miedo" sentido

como consecuencia de desfases clasificatorios, semánticos o de traducción del guaraní al castellano. Siendo esto cierto, ello no invalida mi afirmación de que Capello "sacralizó" la relación existente entre los chiriguanos presentes en la muestra, al presentar a dos de ellos como esposos, y al resto, como familiares de los mismos.

43 Giannecchini en Ibídem: 203.

44 La represión efectuada por aquéllas fue justificada por Chavarría, miembro del partido conservador, señalando: "El principal objetivo de mi misión era sangrienta. Iba a destrozar una muchedumbre salvaje que, a la depravación natural de sus instintos, unía las ferocidades del fanatismo, excitado por el ascendiente de un caudillo salvaje, que haciéndose adorar como un Dios y temer como Rey, logró inflamar el valor de sus súbditos de tal manera que se lanzaban al combate con extraordinario valor y denuedo", en Chavarria, Melchor. 1892. Informe que presenta al Señor Ministro de Gobierno, el Delegado de las Provincias de Tomina, Azero y Cordillera: 4. Sucre: Tip. Del Cruzado. La edición de Calzavarini incluye una carta enviada por el P. Nazareno Dimeco al Superior franciscano del Convento de Tarija, "Relación en torno a los acontecimientos de la insurrección de los chiriguanos de 1892" en Calzavarini, Lorenzo. 1996: 262-263. Clásico texto sobre e suceso que, según comunicación personal de Isabelle Combès-autora de la obra publicada en 2014, Kuruyuki. Cochabamba: Ed. Itinerarios/ Instituto Latinoamericano de Misionología- marcó un antes y un después en la historiografía sobre el mismo, fue el de Sanabria Fernández, Hernando. 1972. Apiaguaiqui-Tumpa. Biografía del pueblo chiriguano y de su último caudillo. Otros trabajos que tratan con cierta atención la cuestión son los de Pifarré, Francisco. 1989. Los Guaraní-Chiriguanos 2. Historia de un pueblo. La Paz: CIPCA; Saignes, Thierry. 1990. Ava y Karai. Ensayos sobre la historia chiriguano (siglos XVI-XX). La Paz: HISBOL y 2007. Historia del pueblo chiriguano, La Paz: IFEA/PLURAL/IRD/ Embajada de Francia; Loayza Valda, Joaquín. 2004. "La sublevación chiriguana de enero de 1892". Sociedad de Estudios Geográficos e Históricos de Santa Cruz. Boletín, 57: 103-117; Combès, Isabelle. 2005. "Las batallas de Kuruyuki. Variaciones sobre una derrota chiriguana”. Boletín del Instituto Francés de Estudios Andinos, 34(2): 221-233; Langer, Erick. 2009. Expecting Pears from an Elm Tree. Franciscan Missions on the Chiriguano Frontier in the Heart of South America, 1830-1949, Durham: Duke Press University. por los vecinos mestizos, impulsores de la expansión del frente ganadero en tierras chaqueñas, afectaba también a los grupos dirigentes bolivianos, altamente preocupados por la resistencia de los comunarios aymara a la aplicación de las leyes de ex-vinculación en las tierras altas promovidas desde fines de la década de 1860 . Estos procesos socioeconómicos fueron impulsados por los empresarios mineros, en el poder desde inicios de la década de 1880 -con el apoyo de los hacendados en tierras altas y ganaderos en el sur, promotores de la expansión de los frentes económicos agropecuarios- rectores de lo que se dado en llamar, en términos políticos, la conformación de Bolivia como estado-nación, con el objetivo de conseguir la plena incorporación del país, de sus producciones económicas, al mercado internacional. La resistencia de importantes sectores de la población indígena en las tierras altas -recordemos la desarrollada por el "temible Wilka"- ${ }^{45}$ provocó un creciente temor al "indio" entre la población blanca y mestiza ante una eventual guerra de razas que, como diversos estudios han señalado, derivó en una "normalización" de la idea de raza en el Estado boliviano configurada por el pensamiento evolucionista, la superioridad de unas razas sobre otras y, en suma, la justificación de la dominación ejercida sobre las consideradas "inferiores". ${ }^{46}$ Es este el contexto que permite leer tanto la historia relatada por Giannechini en el manuscrito enviado a Turín como el relato en imágenes construido por éste cuyo tema central es el reiterado conflicto entre el Estado y la sociedad boliviana y los Chiriguano, entre la civilización y la barbarie -discurso que no está exento de contradicciones como señalé antes y se verá también en las imágenes- y el papel del misionero como mediador entre las partes.

$\mathrm{Y}$, paralelamente, debemos considerar el contexto italiano finisecular, donde se estaba consolidando el proyecto político del Estado nacional, liderado por el Piamonte -abanderado también de un proyecto económico modernizador- y que el certamen turinés quería celebrar. Proyecto éste que había implicado la reducción territorial de los Estados Pontificios y la progresiva pérdida de influencia política y social de la Iglesia católica, que el pontificado de León XIII había enfrentado en diversas esferas - pensamiento e institucionales- sosteniendo la compatibilidad del catolicismo con el progreso y la utilidad de la institución para los proyectos europeos -en el ámbito interno y en su expansión colonial-y

45 Pablo Zárate, conocido como el "temible Willka", líder indígena que, como militar del Ejército boliviano participó en la Guerra Federal junto a los liberales pero con un proyecto propio que pasó, fundamentalmente, por la devolución de las tierras a las comunidades indígenas. Apresado por los vencedores, con el liberal José Manuel Pando en el poder, fue fusilado tras ser declarado culpable de amenazar la estabilidad nacional. Véase Condarco Morales, Ramiro. 1965. Zárate el "temible" Willka, La Paz: Tall. Graf. Bolivianos; Mendieta, Pilar. 2010. Entre la alianza y la confrontación. Pablo Zárate Willka y la rebelión de 1899 en Bolivia. La Paz: Plural/IFEA.

46 Esta racialización -que ha sido estudiada, entre otros, por Egan, Nancy. 2007. "Citizenship, Race and Criminilization. The Proceso Mohoza, 1899-1905", publicado el 17 de septiembre de 2007, en UC San Diego, Center for Iberian and Latin American Studies, http://escholarship. org/uc/item/6680j2k8 (consultado 2.06.2013), y Mendieta, Pilar. 2010, se consolidaría a partir de los sucesos de Mohoza (1899), en el contexto de la Guerra Federal, y el juicio celebrado entonces a los indígenas acusados de la matanza, defendidos por cierto por el abogado Bautista Saavedra. 
latinoamericanos, como señalé al inicio de este trabajo. De ahí el interés de la Iglesia por organizar la Exposición y mostrar tanto las aportaciones culturales realizadas al pensamiento, arte, institucionalidad italiana como las derivadas de la actuación de los misioneros por todo el mundo.

\section{Las imágenes, una representación visual de los Chiriguano}

De acuerdo a la propuesta teórica planteada, debemos señalar, primero y por cuanto se refiere a la producción de las imágenes, que las fotografías remitidas por Giannecchini -se enviaron los negativos (placas), 37 de los cuales fueron reproducidos en Turín-fueron tomadas, bajo la dirección del religioso, ${ }^{47}$ por el fotógrafo napolitano por entonces residente en Tarija, Vincenzo Mascio. Éste acompañó al primero en el viaje que durante 76 días -agosto a septiembre de $1897-$ realizaron ambos por las misiones, ${ }^{48}$ con aparato tecnológico que se hizo llegar desde Buenos Aires y cuyas características técnicas ignoramos. Sabemos que la producción final fue de 115 imágenes, más otras 4 o 5 que se rompieron, ${ }^{49}$ y que todas llevaron la correspondiente leyenda. La agrupación de las fotografías hechas por Calzavarini, a partir del álbum que se encuentra en el Archivo y Biblioteca Nacionales de Bolivia $(A B N B)^{50}$ da la cifra de 26 imágenes protagonizadas por misioneros, 11 de templos, 23 de paisajes urbanos o rurales misionales, 12 escenas de la vida cotidiana de los Chiriguano, 9 fotos de lo que Calzavarini denomina "rasgos de vivencias indígenas", 11 imágenes de maestras y 10 de las escuelas, además de un mapa, lo que resulta un total de 103 fotografías. ${ }^{51}$ Siempre según el historiador y archivista franciscano, las fotografías "confieren un suplemento ideológico a la descripción de la labor franciscana" que "más que lugar eclesiástico [...] es lugar chiriguano". 52

No me interesa avanzar en la lectura interesada de Calzavarini sino señalar que el objetivo de las fotografías enviadas por Giannecchini, y también las recogidas en el texto de Capello, era doble; por un lado, conferir evidencia visual a la historia del proceso civilizatorio desarrollado por los misioneros franciscanos entre los Chiriguano y relatado

\footnotetext{
47 Según nota Giannecchini en el texto, en Calzavarini, Lorenzo. 1996: 159.

48 Pormenores del viaje en Ibídem: 56-58.

49 En realidad se enviaron los negativos y, según señaló Giannec-
} chini, en Turín sólo se revelaron 37 negativos de los cuales solamente se mostraron en la exposición 4 de ellos, en Ibídem: 57.

50 Este Álbum fue preparado por el otrora comisario general de los Colegios de Propaganda Fide en Bolivia, Fr. Sebastián Pifferi -por entonces desafiliado del Colegio potosino y retornado a la Provincia romana a la que había pertenecido originalmente- a partir de los negativos que Giannecchini logró rescatar en Turín y enviar a la Curia Generalicia en Roma. Pifferi hizo imprimir los negativos en Roma a un tal I. Struzzi y preparó dos álbumes; uno -el que se encuentra en el ABNB- para ser dedicado a Luis Paz, ministro en varias coyunturas y firme defensor de las misiones católicas; otro destinado al archivo de la Provincia Franciscana de Roma, en el convento de Aracoeli (Calzavarini, Lorenzo en Álbum. 1995: 16; Calzavarini, Lorenzo. 1996: 64. Estos álbumes tienen dos fotografías no enviadas por Giannecchini, una corresponde a la imagen de Pifferi, la otra a la de Giannecchini junto a los 5 chiriguanos que viajaron con él a Turín.

51 Calzavarini, Lorenzo. 1996: 60.

52 ĺdem. minuciosamente por el franciscano en su Colección y muy sintéticamente por Capello; por otro lado, utilizar las imágenes fotográficas para otorgar objetividad al relato en línea con lo que estaban haciendo antropólogos, geógrafos, médicos, etc, para los que la fotografía era instrumento científico que facilitaba, además, la difusión del conocimiento a un público más vasto. ${ }^{53}$

Como anoté líneas arriba utilizaré sólo las fotografías incluidas en el texto de Capello. Son 7 en total -que no tienen numeración, a diferencia de lo que sucede con las incluidas en el manuscrito enviado por el religioso- con sus correspondientes pies, que se relacionan en el cuadro adjunto, y de las que aquí, por consideraciones editoriales, sólo reproducimos 2 . No está de más añadir que ninguna de las fotografías es espontánea, todas son construidas buscando lo que Berger ha denominado "el momento biográfico o histórico", 54 y persiguen el "efecto de realidad" que, como subraya Barthes, se produce cuando la fotografía es tomada como testimonio de autenticidad y se tiene la impresión de que lo fotografiado es la realidad. ${ }^{55}$

\section{CUADRO 1}

Relación de fotografías sobre las misiones entre los Chiriguano presentadas en Turín, 1898

\begin{tabular}{|c|c|}
\hline $\begin{array}{c}\text { Manuscrito de Fr. Doroteo } \\
\text { Giannecchini }\end{array}$ & Artículo de Amalia Capello \\
\hline $\begin{array}{l}\text { 10. El capataz de la Misión de } \\
\text { Chimeo que muestra al misionero } \\
\text { los diferentes frutos y la produc- } \\
\text { ción de Chimeo }\end{array}$ & $\begin{array}{l}\text { Missioni Francescane della Bo- } \\
\text { livia. Distribuzione dei frutti fatta } \\
\text { dall fattore alla Missione }\end{array}$ \\
\hline $\begin{array}{l}\text { 78. P. Doroteo Giannecchini O.F.M. } \\
\text { colector para la Exposición de las } \\
\text { misiones católicas }\end{array}$ & P. Doroteo Giannecchini \\
\hline $\begin{array}{l}\text { 83. Panorama de la Misión de } \\
\text { Santa Rosa de Cuevo desde el } \\
\text { Norte }\end{array}$ & $\begin{array}{l}\text { Una Missione Francescana di Bo- } \\
\text { livia }\end{array}$ \\
\hline $\begin{array}{l}\text { 91. El baile solemne de los chiri- } \\
\text { guanos en sus fiestas bacanales } \\
\text { [Santa Rosa de Cuevo] }\end{array}$ & $\begin{array}{l}\text { Missioni Francescane della Bo- } \\
\text { livia. } \\
\text { Ballo atorno alla chica }\end{array}$ \\
\hline $\begin{array}{l}\text { 106. Grupo de jornaleros indíge- } \\
\text { nas de la Misión de San Pascual } \\
\text { de Boicovo en un Momento de } \\
\text { descanso }\end{array}$ & $\begin{array}{l}\text { Missioni Francescane della Bo- } \\
\text { livia. } \\
\text { Indigeni Chireguanos }\end{array}$ \\
\hline $\begin{array}{l}\text { 111. Chiriguanos de ambos sexos } \\
\text { ocupados en diversos quehac- } \\
\text { eres y labores en el patio de la } \\
\text { casa-residencia del P. Misionero } \\
\text { [Igüembe] }\end{array}$ & $\begin{array}{l}\text { Missioni Francescane della Bo- } \\
\text { livia. } \\
\text { Donne Chireguanos cariche di } \\
\text { pali }\end{array}$ \\
\hline $\begin{array}{l}\text { Fotografía que no figura en el } \\
\text { manuscrito original }\end{array}$ & $\begin{array}{l}\text { Maestro di danza e direttore del } \\
\text { ballo }\end{array}$ \\
\hline
\end{tabular}

Fuente: Giannecchini en Calzavarini, 1996; Capello en Arta Sacra, 1898: $146-150$.

53 Pauwels, Luc (ed.). 2006; Edwards, Jeanette; Harvey, Penny; Wad, Peter (eds). 2010.

54 Berger, John. 2001. Mirar: 50. Barcelona: Gustavo Gili.

55 Barthes, Roland. 1989. La cámara lúcida. Nota sobre la fotografía. Barcelona: Paidos. Como señala Kossoy, Boris. 2001. Fotografía e historia. Buenos Aires: La Marca, la fotografía obtuvo gran credibilidad desde sus inicios por la semejanza entre el objeto y su representación $y$, por ende, la imagen tomada era la prueba fehaciente que lo retratado existía en la realidad. 
Compartiendo los textos escritos de Giannecchini y Capello el mismo relato etnológico, la diferencia más significativa -en el escrito y en las imágenes- es la relativa a la concreción del primero -siempre referido a una misión y a una actividad concreta- y la generalización, la abstracción de la segunda. La leyenda de las fotografías es clara al respecto cuando Chimeo, Santa Rosa de Cuevo, San Pascual Boicovo, Igüembe devienen "misiones franciscanas de Bolivia", de la misma manera que la imagen de algunos chiriguanos -varones y mujeres- ocupados en quehaceres señalados por Giannecchini devienen para Capello en "mujeres cargadas con palos" -nótese la generalización y, lo más importante, la carga despectiva que implica el genérico "palos"-. Con todo, las fotografías más significativas son la 91 y 106, que aquí se adjuntan.

En la primera imagen correspondiente a la fotografía 91 -Figura 1- el baile solemne de los Chiriguano que señala Giannecchini, deviene para Capello un "baile en torno a la chicha". Más interesante aún es la ampliación de la leyenda del franciscano para quien:

"La fotografía ofrece una idea muy reducida de sus bailes, están en la plaza. Los hombres, puestos en círculo de dos en dos, tomados de una mano y en la otra tienen el mate donde reciben el cangüí de las mujeres que están en medio del círculo cerca de su yambüí. Llevan la aguá en forma de corona sobre su cabeza con flecos que caen sobre sus espaldas, al pecho agujones de plata pura, collares y el rostro pintado de rojo. Más atrás los cantores del ayarisse rodeados por otros indios curiosos. Un indio montado en su caballo y vestido de guerrero con lanza en la mano observa a los bailarines; otro al lado de su caballo, ensillado a la manera india, mira a los bailarines. Están vestidos con pieles curtidas. Este vestido les sirve para ir de cacería como para ir a la guerra". ${ }^{56}$

\section{FIGURA 1}

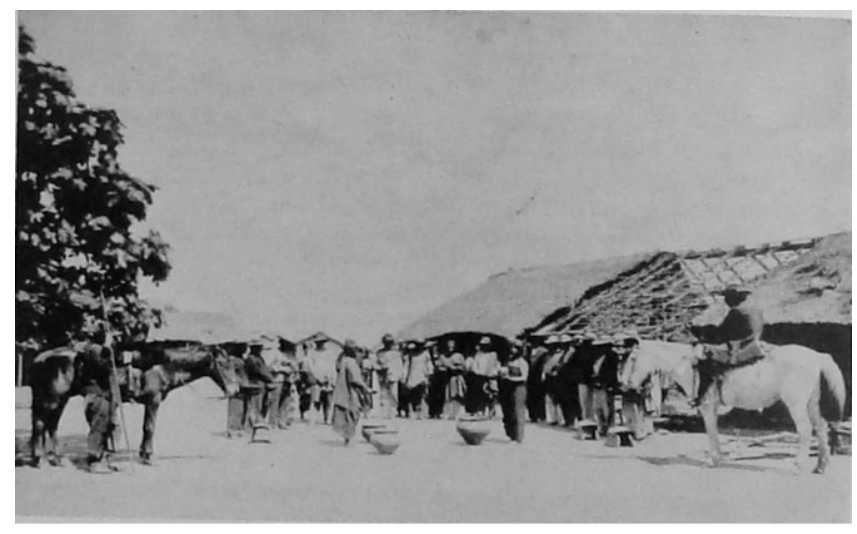

Fuente. Álbum. 1995: 158

La sintética y clara descripción etnográfica hecha por Giannecchini a propósito del baile -del que no se explica, por otra parte, el ritual del que forma parte- deviene un confuso, genérico y, cuanto menos parcialmente inventado relato por Capello, a propósito de una fotografía, inexistente en la colección enviada por el franciscano a Turín, no obstante el artículo de Capello sí incluya la imagen a la que se

56 El énfasis está en el original. Leyenda en Borrador-Manuscrito de Giannecchini, p. 062, recogida en Calzavarini, 1996: 236. refiere la leyenda. La autora italiana señala a propósito de aquella imagen que:

"Fra gli usi piú curiosi é certamente il ballo, pure rappresentato da una illustgrazione. I Chireguanos [sic] danzano attorno a quattro grandi orciuoli colmi di chica, liquore fatto con grano turco fermentato, e danzano in cadenza al ritmo d'una canzone, secondo le norme del maestro di danza, il quale regge un grande ombrello di piume, e colla canna batte la solfa. Questa danza veniva forse anche fatta a scopo religioso, ma in quanto alle loro pratiche esterne di culto sono cosi poche ed inverte da non poternne parlare con sicurezaa. Riconoscono un genio buono ed uno cattivo, rivolgono qualche preghiera al sole e non vanno piú oltre". ${ }^{57}$

\section{FIGURA 2}

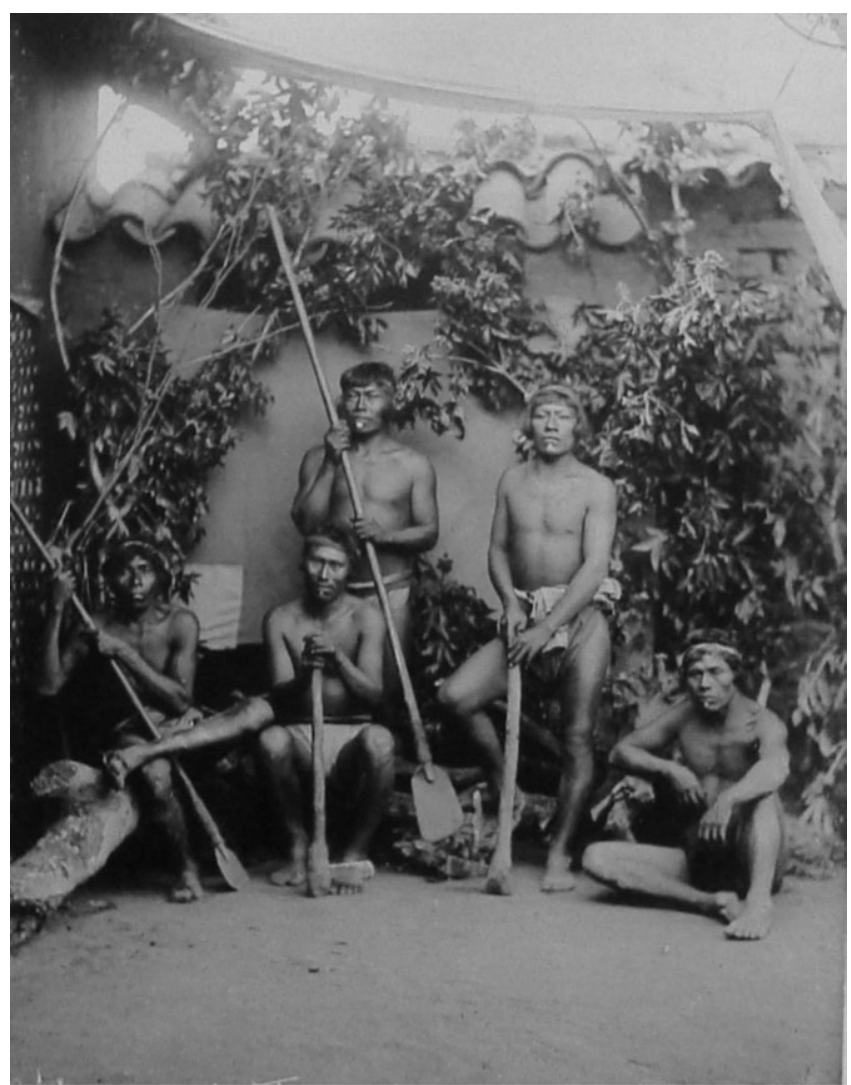

Fuente. Álbum, 1995: 175

En la segunda imagen, fotografía 106 -Figura 2- el específico "Grupo de jornaleros indígenas de la misión de San Pascual de Boicovo en un momento de descanso" en la que los Chiriguano posan al modo "antiguo" - sin duda resultado del interés de Giannecchini por mostrar a los antiguos bárbaros ahora jornaleros y sometidos a hábitos regulares de trabajo- ${ }^{58}$ deviene, en el relato de Capello, un tipo

57 Capello, Amalia. 1898: 147.

58 Dos de los personajes posan con un cavador y una pala; otros dos sostienen sólo los mangos sin la correspondiente hoja de hierro (azada, pala, cavador). Según información, que agradezco, de uno de los evaluadores, tres décadas más tarde Alfred Métraux constató que los Chiriguano utilizaban las palas occidentales para su trabajo en los ingenios o en la apertura y mantenimiento de vías camineras, y su tradicional palo cavador (tsirakua) para su trabajo en el chaco de maíz, en Métraux, Alfred. 1930. "Études sur la civilisation des indiens Chiriguano". Revista del Instituto de Etnología de la Universidad de Tucumán, 1: 335. 
generalizado, una abstracción en ese caso referida a "Indios chireguanos" sobre cuyo vestido dice "é molto primitivo [...] ed una sola fascia cinge i loro fianchi" si bien agrega que cuando "cominciano ad estimare la civiltà adottano dei vestiti, e se non possono acquistare dei panni all'uso europeo, si fanno delle giubbe e dei calzoni con grosso cuoio". ${ }^{59}$ Abstracción que, notemos, incluye las secuencias desnudezprimitivismo, vestido-civilización.

\section{EpíLOgo}

Los superiores franciscanos en Italia, Bolivia y Tarija consideraron que la presencia de la colección enviada por Giannecchini había sido un gran éxito. ${ }^{60}$ Sin embargo, el religioso, de retorno en Bolivia, se mostró muy decepcionado acerca del eco obtenido por las misiones en el certamen pues, según señala Calzavarini "La ilusión [de Giannecchini] de hacer de Turín una caja de resonancia a favor de los Chiriguano resultó una amarga desilusión" 61 pues, siempre según el autor, el "mensaje religioso" fue oscurecido por los festejos del cincuentenario -en alusión a la conmemoración de la carta constitucional aprobada en 1848- y, lo que Calzavarini denomina "prejuicios racísticos [sic] del 'salvajismo' y que la misma dimensión misionera traslució 'barbarizada' respecto a la pretendida civilización moderna", 62 aunque sin dar los argumentos correspondientes.

En conclusión, el relato etnológico construido por Giannecchini, y del que participa Capello, es el positivista, dominante en el pensamiento europeo finisecular, en el que las tesis evolucionistas aplicadas a la sociedad permiten plantear la mutación de la barbarie -"gente feroz y salvaje", "bárbaros", "hombres de la selva" que salen "de sus matorrales", "hordas salvajes- a la civilización -"hombres útiles a sí mismos, a la religión y a la patria", "artesanos, cristianos, ciudadanos"-. Las categorías por ellos utilizadas tienen que leerse, como dijimos al inicio, en esa clave ideológica. Por lo que respecta a las fotografías recogidas en los textos de ambos autores, el objetivo perseguido por éstos era doble; por un lado, evidenciar, visualmente, la historia del proceso civilizatorio desarrollado ampliamente en el caso de Giannecchini, y sucintamente en el caso de Capello; por otro lado, otorgar objetividad al relato en línea con lo que estaban haciendo antropólogos, geógrafos, médicos, etc. en la Europa finisecular.

Sin embargo, hay varias diferencias significativas entre ambos autores tanto en el texto escrito como en las imágenes visuales. La primera, referida al relato, que en Giannecchini es "específico", "concreto" y atiende, exclusivamente, al proceso conquistador y reduccionista implementado por los franciscanos entre los Chiriguano, con las categorías correspondientes. Este relato deviene, en el texto de Capello, una abstracción aplicada a todos los misioneros que desarrollan sus actividades en el mundo.

La segunda, relativa a las fotografías. En ambos casos son utilizadas para conseguir el efecto de objetividad pero,

\footnotetext{
59 Capello, Amalia. 1898: 147.

60 Calzavarini, Lorenzo. 1996: 58.

61 Ibídem: 51.

62 Ibídem: 58.
}

sin embargo, difieren en sus leyendas en las que acaece la misma operación que vimos en el relato. Mientras en el caso de Giannecchini se refieren a actividades específicas que se desarrollan en pueblos misionales concretos, en el de Capello, tales actuaciones devienen genéricas, igual como las referencias a las mismas para todas las misiones.

La tercera diferencia incluye las dos anteriores y se refiere tanto al texto como a las fotografías. Capello, en sintonía con los objetivos perseguidos por los organizadores de la Exposición misional, publicitaba la acción misionera de los franciscanos -mediadores culturales- para la transformación de los salvajes chiriguanos en individuos civilizados, y hacía del "exitoso" caso chiriguano una generalización aplicable a la actividad desarrollada por los misioneros en todo el orbe; los significados del texto escrito y de las imágenes son claros en mostrar la superioridad de una raza sobre otra y justificar la dominación y el colonialismo -externo e interno- sobre las razas consideradas inferiores. De ahí la necesaria actuación de las "sociedades civilizadas" sobre las "sociedades primitivas". Por el contrario, Giannecchini -opuesto a la secularización y a la modernidad presente en Europa y América Latina, Bolivia en el caso que él trataba- en una clara contradicción, justificaba la conquista y reducción de los bárbaros chiriguanos y publicitaba los éxitos conseguidos por los franciscanos al haber conseguido hacer de ellos "artesanos", "cristianos", "civilizados"; sin embargo, paralelamente, denunciaba a los colonos y a la sociedad blanco-mestiza boliviana barbarizada que corrompía a los indígenas y destruía la civilización conseguida por los misioneros.

\section{BiBLIOGRAFÍA}

A.C. 1898. "Gli oggetti esposti nella Mostra delle Missioni", en Arte Sacra: 305-306. Torino: Roux Frassati e Co.

Álbum. 1995. - fotográfico de las misiones franciscanas en la República de Bolivia, a cargo de los Colegios Apostólicos de Tarija y Potosí, 1898, dedicado a Luis Paz. La Paz: Ed. Banco Central.

Arte Sacra. 1898. Torino: Roux Frassati e Co.

Barthes, Roland. 1989. La cámara lúcida. Nota sobre la fotografía. Barcelona: Paidos.

Berger, John. 2001. Mirar. Barcelona: Gustavo Gili.

Blanchard, Pascal; Boëtsch, Gilles; Snoep, Nanette J. (eds.). 2011. Exhibitions. L'invention du sauvage. París: Actes Sud and Musée du Quai Branly.

Braun, Marta. 2007. "La photographie et les sicences de l'observation (1845-1900)", en André Gunthert and Michel Poivert (eds.). L'art de la photographie des origines à nos jours: 140-177. París, Citadelles \& Mazenod.

Bottaro, Mario. 1984. Genova 1892 e le celebrazione colombiane. Génova: Francesco Pirella Ed.

Burke, Peter. 2001. Visto y no visto. El uso de la imagen como documento histórico. Barcelona: Crítica.

Burris, John P. 2001. Exhibiting Religion: Colonialism and Spectacle at International Expositions 1851-1893. Charlotesville/Londres: University Press of Virginia.

Capello, Amalia. 1898. “Le Missioni Francescane nell'America del Sud. Bolivia e chireguanos", en Arte Sacra: 146-150. Torino: Roux Frassati e Co.

Calzavarini, Lorenzo. 1996. Historia natural, etnografía, geografía, lingüística del Chaco boliviano, 1898. Tarija: Fondo de Inversión Social / Centro Eclesial de Documentación.

Coombes, Annie E. 1994. Reinvening Africa: Museums, Material Culture and Popular Imagination in Late Victorian and Edwardian England. New Haven/Londres: Yale University Press.

Combès, Isabelle. 2005. "Las batallas de Kuruyuki. Variaciones sobre una derrota chiriguana". Boletín del Instituto Francés de Estudios Andinos, 34(2): 221-233. 
Combès, Isabelle, 2014. Kuruyuki. Cochabamba: Ed. Itinerarios/ Instituto Latinoamericano de Misionología.

Condarco Morales, Ramiro. 1965. Zárate el "temible" Willka. La Paz: Tall. Gráf. Bolivianos.

Chartier, Roger. 1992. Historia Cultural: entre práctica y representación. Barcelona: Editorial Gedisa.

Chartier, Roger. 1996. Escribir las prácticas. Foucault, de Certeau, Marin. Buenos Aires: Manantial.

Chavarría, Melchor. 1892. Informe que presenta al Señor Ministro de Gobierno, el Delegado de las Provincias de Tomina, Azero y Cordillera. Sucre: Tip. Del Cruzado.

De Certeau, Michel. 2000. "Teorías del arte de hacer", en Michel de Certeau. La invención de lo cotidiano: 49-99. México: Universidad Iberoamericana/Instituto Tecnológico y de Estudios Superiores de Occidente, Vol. 1.

Dube, Saurabh. 2001. Sujetos subalternos: Capítulos de una historia Antropológica. México: El Colegio de México.

Edwards, Elizabeth (ed.) 1992. Anthropology \& Photography, 18601920. New Haven: Yale University Press.

Edwards, Jeanette; Harvey, Penny; Wad, Peter (eds.) 2010. Technologized Images. Technologized Bodies. Oxford: Berghahn Books.

Egan, Nancy. 2007. “Citizenship, Race and Criminilization. The Proceso Mohoza, 1899-1905", en UC San Diego, Center for Iberian and Latin American Studies, http://escholarship.org/uc/item/6680j2k8.

Erlmann, Veit. 1999. "«Spectatiruak Kyst»: The African Choir in England, 1891-1893", en Lindfords Bernth (ed.). African on Stage: Studies in Ethnological Show Business: 107-134. Bloomington: Indiana University Press.

Findling, John E. y Pelle, Kimberly D. (eds.) 2008. Encyclopedia of World's Fairs and Expositions. Jefferson/Londres: Mc Farland \& Company, Inc. Publishers.

García Jordán, Pilar. 2012. "La representación de los Guarayos en la 'Esposizione d'Arte Sacra e delle Missioni ed Opere Cattoliche" (Turín, 1898)". Boletín Americanista, LXII.2, 65: 107-129.

Ghirardi, G. B. 1898. “Come nacque l'esposizione d’Arte Sacra”, en Arte Sacra: 2. Torino: Roux Frassati e Co.

Greenhlagh, Paul. 1988. Ephemeral vistes. The expositions universelles, great exhibitions and world's fairs, 1851-1939. Manchester: Manchester University Press.

Gulinelli, A. 1898. Guida dell' Esposizione Generale dell'Arte Sacra in Torino con Pianta della Città e delle Esposizioni, compilata dal Cav. Avv. -, Sotto Segretario della Camera di Commercio di Torino già Direttore degli Uffici sull'Esposizione 1884. Torino/Roma/ Milano/ Firenze/Napoli: Ditta G. B. Paravia e Comp.

Kossoy, Boris. 2001. Fotografía e historia. Buenos Aires: La Marca.

Langer, Erick. 2009. Expecting Pears from an Elm Tree. Franciscan Missions on the Chiriguano Frontier in the Heart of South America, 1830-1949. Durham: Duke Press University.

Loayza Valda, Joaquín. 2004. "La sublevación chiriguana de enero de 1892". Sociedad de Estudios Geográficos e Históricos de Santa Cruz. Boletín, 57: 103-117.
Marin, Louis. 1981. Le Portrait du Roi. París: Editions de Minuit.

Marin, Louis. 1993. Des pouvoirs de l'image: gloses: 9-22. París: Editions du Seuil.

Marin, Louis. 1994. De la représentation. París: Gallimard/Le Seuil.

Mendieta, Pilar. 2010. Entre la alianza y la confrontación. Pablo Zárate Willka y la rebelión de 1899 en Bolivia. La Paz: Plural / IFEA.

Métraux, Alfred. 1930. "Études sur la civilisation des indiens Chiriguano". Revista del Instituto de Etnología de la Universidad de Tucumán, 1: 295-493.

Pauwels, Luc (ed.). 2006. Visual Cultures of Science: rethinking representational practices in knowledge building and sciences communication. Hanover: University Press of New England.

Pifarré, Francisco. 1989. Los Guaraní-Chiriguanos 2. Historia de un pueblo. La Paz: CIPCA.

Poole, Deborah. 1997. Visions, race, and modernity: a visual economy of the Andean image world. Princeton: Princeton University Press.

Rydell, Robert W. 1984. All the World's a Fair. Visions of Empire as American International Exposition, 1876-1916. Chicago: The University of Chicago Press.

Saignes, Thierry. 1990. Ava y Karai. Ensayos sobre la historia chiriguano (siglos XVI-XX). La Paz: HISBOL.

Saignes, Thierry. 2007. Historia del pueblo chiriguano, La Paz: IFEA/ PLURAL/IRD/Embajada de Francia.

Sanabria Fernández, Hernando. 1972. Apiaguaiqui-Tumpa. Biografía del pueblo chiriguano y de su último caudillo. La Paz: Los Amigos del Libro.

Sánchez Gómez, Luis Ángel. 2006. “Martirologio, etnología y espectáculo: la Exposición Misional Española de Barcelona (19291930)". Revista de Dialectología y Tradiciones Populares, LXI, 1: 63-102.

Sánchez Gómez, Luis Ángel. 2007. “Por la Etnología hacia Dios: la Exposición Misional Vaticana de 1925". Revista de Dialectología y Tradiciones Populares, LXII, 2: 63-107.

Sánchez Gómez, Luis Ángel. 2011. "Imperialismo, fe y espectáculo: la participación de las iglesias cristianas en las exposiciones coloniales y universales del siglo XIX". Hispania, LXXI, 237: 153-180.

Semeria, P.G. 1898. "Le Missioni Cattoliche all'Esposizione d'Arte Sacra", en Arte Sacra: 10-11. Torino: Roux Frassati e Co.

Sontag, Susan. 1996. Sobre la fotografía. Barcelona: Edhasa.

Stoklund, Bjarne. 1994. "The role of the International Exhibitions in the construction of national cultures in the 19th. Century". Ethnologica Europaea, 24, (1): 35-44.

Yengoyan, Aram. 1994. “Culture, Ideology and World's Fairs: Colonizer and Colonized in Comparative Perspectives", en R. W. Rydell y N. Gwinn (eds.). Fair Representations: World's Fairs and the Modern World: 62-83. Amsterdam: VU University Press.

Zaccone, Gian Maria. 1996. “L'Esposizione d'arte sacra del 1898 a Torino tra religione e politica". Studi Piamontesi, XXV-1: 71-102.

Zamorano Villarreal, Gabriela. 2011. “Fisonomía de traidor: Fotografía y la racialización de los indígenas bolivianos por la expedición Créqui-Montfort (1903)". Anuario de estudios bolivianos, archivísticos y bibliográficos, 17: 635-674. 